\title{
고출력 $\mathrm{GaN} \mathrm{RF}$ 전력증폭 소자 공정 양산 개발
}

\section{High Power GaN RF Device Manufacturing Process Development}

\author{
이상민 ${ }^{* 11}$, 전병철 ${ }^{1)}$, 최철순 ${ }^{1)}$, 정혜영 ${ }^{1)}$, 권호상 ${ }^{2)}$ \\ Sangmin Lee,1) ${ }^{*}$ Byoungchul Jun ${ }^{1)}$, Chulsoon Choi ${ }^{1)}$, Hyeyoung Jung ${ }^{1)}$, Hosang Kwon ${ }^{2)}$
}

$$
\text { [ 초록 ] }
$$

본 보고서는 국책과제의 결과를 요약한 것으로 $0.4 \mathrm{um}$ 게이트 길이를 갖는 고출력의 $\mathrm{RF}$ 소자를 양산수준의 신뢰성을 확보하도 록 공정기술을 개발하는데 목적이 있다. 지금까지의 과제와 다른 점은 성능 목표 뿐 아니라 신뢰성과 수율을 목표로 설정함으로써 같은 성능의 소자를 대량으로 제작하여 그 재현성과 신뢰성을 확인하고 추가적인 경제성을 확보하기 위하여 크기가 큰 고출력 소자 의 수율을 일정이상이 되도록 설정함으로써 그간의 부품개발 과제가 성능목표 달성에만 국한함으로써 목표를 달성하였으나 그 부품 은 국내에 존재하지 않는 문제점을 해결하여 실질적으로 소자의 생산이 국내에서 가능하도록 하는 데에 있다. 5 년간의 개발 결과로 게이트 너비 $0.7 \mathrm{~mm}$ 의 PCM(process control monitoring)소자에 대하여 문턱전압(Vth) $-2.7 \mathrm{~V}$, 항복전압 $200 \mathrm{~V}$ 이상, 최대포화 전류 $950 \mathrm{~mA} / \mathrm{mm}$, 최대 트랜스컨덕턴스 $250 \mathrm{mS} / \mathrm{mm}$, ft $19 \mathrm{GHz}$, fmax $41 \mathrm{GHz}, 3.5 \mathrm{GHz}$ 에서의 소신호 이득 $16.5 \mathrm{~dB}$, 최대 출력 $8 \mathrm{~W} / \mathrm{mm}$, 전력부가효율 53\%의 소자특성을 확인하였다. $\mathrm{PCM}$ 소자의 $\mathrm{RF}$ 성능은 $\mathrm{CW}$ (continuous wave)모드에서 측정하였다. 고출력 소자는 총 게이트 너비 $3.5 \mathrm{~mm}$ 인 단위소자를 기반으로 제작하였다. 단위소자들은 약 $>20 \mathrm{~W}$ 의 출력을 보이며 대량으로 제작 한 단위소자에 대하여 가속수명시험을 포함하는 다양한 신뢰성 시험을 성공적으로 통과하였다. 단위소자 8 개를 병렬로 연결하여 제 작한 고출력 소자를 제작하여 S-band $400 \mathrm{MHz}$ 대역에서 $186.5 \mathrm{~W}$ 이상의 출력, $13.5 \mathrm{~dB}$ 이상의 소신호 이득, $63.6 \%$ 이상의 드레 인 효율을 측정하였다. $180 \mathrm{~W}$ 급의 고출력 소자도 대량으로 생산하여 고온동작시험과 온도변화, 고온저장 등의 환경시험을 통과하였 으며 공정최적화를 통해 최종단계에서 웨이퍼당 83 92\%의 수율을 확보하였다.

\section{[ ABSTRACT ]}

In this report, the results of a government supported project have been summarized. The purpose of the project was to develop a fabrication process of high power GaN RF devices with 0.4 um gate length at S-band frequency ranges. The most important fact which makes this project different from previous government funded projects on GaN HEMT device development in Korea is that this project is not only asking for the performance of the device but also for the reliability and yield of the devices which are the two crucial factors for manufacturing and mass production. Through the hard work for the last 5 years, GaN HEMT process has been developed in Wavice Inc., and it shows excellent performance and reliability. The process control monitoring devices with $0.7 \mathrm{~mm}$ gate periphery show $-2.7 \mathrm{~V}$ threshold voltage, $>200 \mathrm{~V}$ breakdown voltage, $950 \mathrm{~mA} / \mathrm{mm}$ maximum saturation current, $250 \mathrm{mS} / \mathrm{mm}$ maximum trans-conductance, $19 \mathrm{GHz} \mathrm{ft}, 41 \mathrm{GHz}$ fmax, $16.5 \mathrm{~dB}$ small signal gain, 8W/mm maximum output power density, 53\% power added efficiency. The RF performances of PCM devices were measured with continuous wave mode. The high power devices were fabricated by connecting unit cell devices with $3.5 \mathrm{~mm}$ gate periphery in parallel. $3.5 \mathrm{~mm}$ devices show $>20 \mathrm{~W}$ output power and $3.5 \mathrm{x} 8=28 \mathrm{~mm}$ devices show $>186.5 \mathrm{~W}$ output power, $>13.5 \mathrm{~dB}$ small signal gain, $>63.5 \%$ drain efficiency over $400 \mathrm{MHz}$ bandwith in S-band with pulsed input signal with 15\% duty cycle.. Both unit cells and 180W high power devices passed MIL-STD based reliability tests. The 180W devices shows 83 92\% yield from the on wafer test.

Key Words : GaN, HEMT(High Electron Mobility Transistor), 양산(Manufacturing), 레이다(Radar), 신뢰성(Reliability), 수율 (Yield),

1. 서 론
초연결 사회를 기반으로 하는 4차 산업혁명 시대의 도래에

따라 인공지능(Artificial Intelligence), 사물인터넷 (Internet of Things), 증강현실(Augmented Reality), 가상현실(Virtual
Reality), 무인운송(Driverless Delivery) 등의 기술이 빠르게 현실화 하고 있다. 이러한 초연결 사회를 이루기 위해서는 빅 데이터(big data) 클라우드 컴퓨팅(Cloud Computing)등의 서 비스와 이를 가능하게 해줄 초고속 컴퓨터, 대용량 저장장치,

1)(주) 웨이비스 첨단소자 연구소(Advanced Device Research Center, Wavice Inc) 2)국방과학연구소(Agency for Defense Development, Korea) *Corresponding author, E-mail: smlee@wavice.com Copyright (c) The Korean Institute of Defense Technology

Received: November 17, $2020 \quad$ Revised: Accepted: December 7, 2020 
초고속 네트워크 등이 가능해 져야 한다. 이중 초고속 네트워

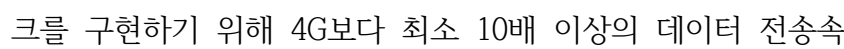
도를 갖는 $5 \mathrm{G}$ 통신 기술이 일반화 되어야 한다. ${ }^{[1]} 5 \mathrm{G}$ 통신에 서는 데이터의 전송속도를 높이기 위하여 더 높은 주파수에서 더 넓은 대역폭을 이용하여 통신을 수행하여야 하기 때문에 $3.4 \mathrm{GHz}$ 이상의 주파수에서 5G용 통신 주파수의 경매가 이루 어지고 있는 것이다. ${ }^{[2]}$ 이를 위해서는 $3 \mathrm{GHz}$ 이하의 주파수에 서 사용되던 기존의 $\mathrm{Si} \mathrm{LDMOS}$ 신호 증폭기로는 $5 \mathrm{G}$ 이동통신 을 지원할 수 없다는 것을 의미한다. 이러한 초고속 통신을 가 능하게 해 주는 새로운 소자가 바로 GaN HEMT 소자이다. 그 림 1에 4차 산업혁명과 $\mathrm{GaN} \mathrm{HEMT소자의} \mathrm{상관관계를} \mathrm{표시하}$ 였다.

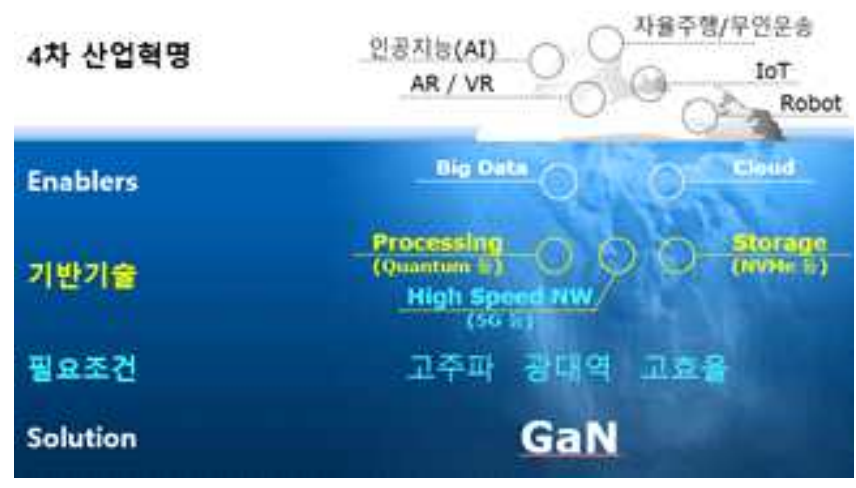

그림 1. 4차 산업혁명과 GaN HEMT소자의 필요성

Fig. 1. The 4th Industrial Revolution and the nature of GaN HEMT devices

표 1에는 고주파에서 고출력 소자를 가능하게 하는 $\mathrm{GaN}$ HEMT소자의 물질 특성을 Silicon 과 비교 요약하였다. GaN $\mathrm{HEMT}$ 는 $\mathrm{Si}$ 소자에 비하여 밴드갭 에너지가 3 배 이상 높고, 전 자의 최대 이동속도가 3 배 가까이 빠르며 항복 전기장이 10 배 이상 커 고주파에서도 높은 동작 전압과 고출력을 낼 수 있는 소자가 가능해 진다. 특히 $\mathrm{GaN}$ 소자는 그 기판을 $\mathrm{Si}$ 에 비하여 열전도율이 2 배 이상 높은 $\mathrm{SiC}$ 를 기판으로 하고 있어 고출력 에서 동작시켜도 효과적으로 열 방출을 시켜 소자를 안정적으 로 동작시킬 수 있게 된다.

표 1. Silicon소자와 GaN HEMT소자의 전기적, 열적 물성 비교. 밴드갭 에너지(Eg), 전자 이동도 $(\mu \mathrm{s})$, 전자 포화 속도 $(\mathrm{Vs})$, 항복 전기장 $(\mathrm{EB})$, 기판의 열전도도 $(\lambda \mathrm{s}, \mathrm{GaN}$ 의 경우에는 $\mathrm{SiC})$

Table 1. Comparison of electrical and thermal properties of silicon devices and GaN HEMT devices. Bandgap energy (Eg), electron mobility ( $\mu$ s), electron saturation rate $(\mathrm{Vs})$, electric breakdown field (EB), thermal conductivity of the substrate $(\lambda \mathrm{s}, \mathrm{SiC} \text { for } \mathrm{GaN})^{[3]}$

\begin{tabular}{|c|c|c|c|c|c|}
\hline 소자 & $\begin{array}{c}\mathrm{E}_{\mathrm{g}} \\
(\mathrm{eV})\end{array}$ & $\begin{array}{c}\mu_{\mathrm{s}} \\
\left(\mathrm{cm}^{2} / \mathrm{Vs}\right)\end{array}$ & $\begin{array}{c}\mathrm{V}_{\mathrm{s}}\left(\mathrm{x} 10^{7}\right. \\
\mathrm{cm} / \mathrm{s})\end{array}$ & $\begin{array}{c}\mathrm{E}_{\mathrm{B}}\left(\mathrm{x} 10^{6}\right. \\
\mathrm{V} / \mathrm{cm})\end{array}$ & $\begin{array}{c}\lambda_{\mathrm{s}} \\
(\mathrm{W} / \mathrm{mK})\end{array}$ \\
\hline Silicon & 1.11 & 1500 & 1.0 & 0.3 & 150 \\
\hline
\end{tabular}

\begin{tabular}{|l|l|l|l|l|l|}
\hline $\mathrm{GaN}$ & 3.42 & 2000 & 2.7 & 3.3 & 380 \\
\hline
\end{tabular}

물질 특성 면에서 볼 때 이처럼 뛰어난 특성을 가지고 있으나 이러한 $\mathrm{GaN}$ HEMT소자가 본격적으로 상용화되기 시작한 것 은 약 5-6년 전의 일이다. ${ }^{[4]}$ 미국과 일본에서는 1990년대 말 부터 국가적인 지원을 통해 대학과 연구소에서 연구가 시작되 어 2000년대 중반부터 본격적으로 기업체에서 개발에 착수 하 였다. ${ }^{[5]}$ 미국에서 본격적인 대량 생산이 시작된 것은 2013년부 터이다. ${ }^{[6]}$ 한국에서도 대학과 연구소를 중심으로 2004년부터 연구 개발을 시작하였으며 ${ }^{[7]}$ 기업체에서 양산을 위한 개발이 시작된 것은 2015년 말 부터이다. ${ }^{[8]}$ 본 논문은 2015년11월부 터 2020년 10월까지 국방과학 연구소의 지원을 받아 수행되어 성능뿐 아니라 신뢰성과 수율의 목표항목을 모두 성공적으로 달성한 $\mathrm{GaN} \mathrm{HEMT} \mathrm{양산} \mathrm{개발} \mathrm{과제의} \mathrm{결과에} \mathrm{대한} \mathrm{보고이다.}$

\section{2. 소자의 설계와 제작}

고주파 고출력의 $\mathrm{RF} \mathrm{GaN}$ 소자를 제작하기 위해서는 $\mathrm{SiC}$ 기판위에 버퍼와 채널층으로 작동하는 $\mathrm{GaN}$ 와 이보다 bandgap이 큰 $\mathrm{AlGaN}$ 등의 장벽층을 포함하는 에피가 성장된 기판이 필요하다. 이러한 에피기판 위에 소스, 게이트 드레인 을 포함하는 HEMT소자의 각 구성성분을 특정한 주파수에서 특정한 $\mathrm{RF}$ 성능을 갖도록 디자인하고 반도체 공정을 이용하여 구현하여야 한다. 본 장에서는 소자개발에 사용된 에피의 구조 와 제작 공정에 대하여 설명하고자 한다.

\section{1 에피와 소자의 구조}

그림 2에 소자제작에 사용된 에피의 구조를 나타내었다. $\mathrm{SiC}$ 기판과 $\mathrm{GaN}$ 에피는 약 $4 \%$ 의 격자 부정합을 가지고 있다. 따라서 단결정 $\mathrm{GaN}$ 에피를 결함을 줄이면서 성장하기 위해서 는 두꺼운 버퍼층이 필요하게 된다. 또한 누설 전류를 줄이기 위하여 버퍼층은 고저항이어야 한다. 기판으로 사용하는 $\mathrm{SiC}$ 도 고순도 단결정 형태(High Purity Semi-Insulating, HPSI) 의 고저항 기판을 사용하였다.

본 개발에 사용된 에피는 Cree사에서 성장되었으며 약 0.1 $\mathrm{um}$ 의 시드층(seed layer)과 $2 \mathrm{um}$ 의 $\mathrm{GaN}$ 층을 가지고 있다. 이중 약 $1.8 \mathrm{um}$ 의 아래쪽 고저항 층은 $\mathrm{Fe}$ 불순물이 첨가되어 고저항 특성을 보이며 위쪽 약 $0.2 \mathrm{um}$ 가 불순물이 적은 채널 층을 형성한다. 얇은 채널층에 2 차원 전자가스(2 dimensional electron gas, 2DEG)를 형성하기 위하여 밴드갭이 큰 $\mathrm{AlxGa1-xN}$ 배리어층을 형성하였다. 사용된 배리어층의 두께 는 $24 \mathrm{~nm}, \mathrm{Al}$ 함량 $\mathrm{x}$ 는 0.22 를 사용하였다. 배리어층의 효 과를 극대화하기 위하여 $\mathrm{AlxGa1-xN}$ 배리어층과 $\mathrm{GaN}$ 채널 층 사이에 $1 \mathrm{~nm}$ 두께의 $\mathrm{AlN}$ 층을 추가하였다. 


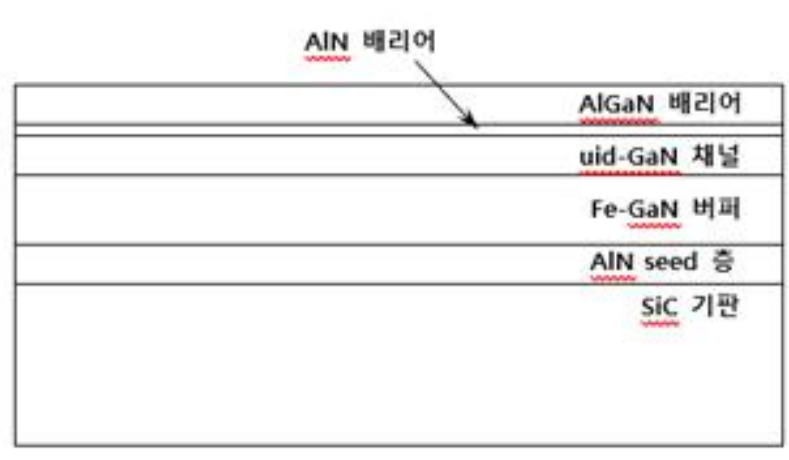

그림 2. 에피 구조. 고저항 $\mathrm{SiC}$ 기판, $100 \mathrm{~nm}$ 두께의 $\mathrm{AlN}$ seed 층, 두께 약 $1.8 \mathrm{um}$ 의 고저항 Fe-doped GaN 버퍼층, 약 $0.2 \mathrm{um}$ 두께의 인위적 도핑이 되지 않은(Un-intentionally doped, uid) $\mathrm{GaN}$ 채널층, $\mathrm{AlN}$ 배리어층 $10 \AA ⿻ 22 \% \mathrm{Al}$ 함량의 $\mathrm{AlGaN}$ 배리어 $240 \AA$ 으로 구성되어 있음.

Fig. 2. Epi structure. High resistance $\mathrm{SiC}$ substrate, 100 $\mathrm{nm}$ thick AlN seed layer, high resistance Fe-doped GaN buffer layer about 1.8 um thick, Un-intentionally doped, uid GaN channel layer about 0.2 um thickness, AlN barrier Layer $10 \AA$, consisting of $240 \mathrm{~A} \mathrm{AlGaN} \mathrm{barrier}$ with $22 \% \mathrm{Al}$ content.

그림 3은 소자의 구조를 보여주는 개략적인 단면도이다. 게 이트의 길이는 $0.4 \mathrm{um}$ 이고 소스와 드레인의 간격은 $5.9 \mathrm{um}$, 소스와 게이트의 간격은 $1 \mathrm{um}$ 이다.

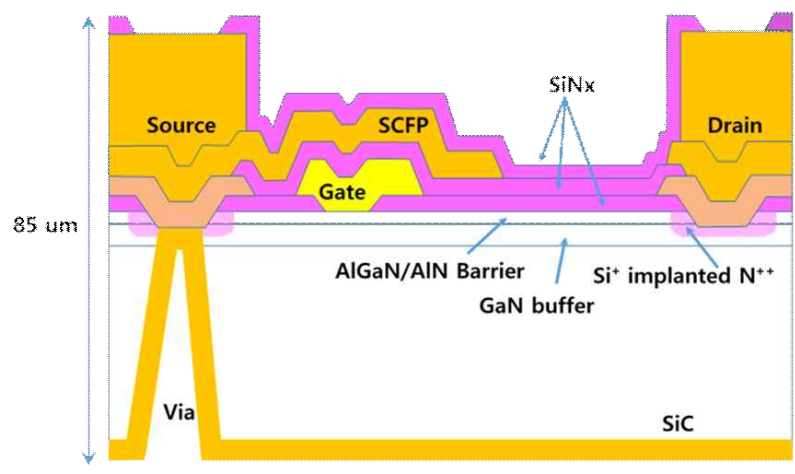

그림 3. 소자의 구조를 보여주는 단면 개략도

Fig. 3. Sectional schematic diagram showing the structure of the device

소스와 드레인 오믹은 $\mathrm{Si}$ 이 첨가된 $\mathrm{n}$-type 영역위에 형성하 였고, 소스연결 필드 플레이트(Source Connected Field Plate, SCFP)를 게이트 금속위에 $\mathrm{SiNx}$ 절연막을 사이에 두고 형성하였으며 최종 금속은 고출력 동작시 전류의 흐름을 담보 할 수 있도록 약 $5 \mathrm{um}$ 두께의 금도금 막으로 형성하였다. 마 지막 보호막(Passivation layer)은 $\mathrm{SiNx}$ 절연층을 사용하였다. 기판의 최종 두께는 $85 \mathrm{um}$ 이고 기판을 관통하는 비아를 통해 약 $5 \mathrm{um}$ 두께의 금도금으로 형성한 후면 금속막과 소스 오믹 금속이 직접 연결될 수 있도록 하였다.

\section{2 제조 공정}

소자는 웨이비스가 가지고 있는 4인치 웨이퍼 전용의 양산 라인을 통하여 제작되었다. 소스와 드레인의 오믹 접촉은 $\mathrm{Si}$ 이온주입을 통하여 n-type으로 도핑된 영역에 형성하였다. 오 믹 금속은 $\mathrm{Si} / \mathrm{Ni}$ 다층막을 열처리하여 합금형태로 형성하였고 게이트 금속은 Ni Schottky 접촉을 사용하였다. 소자의 최대 전기장을 낮추어 항복전압을 증가시키고 신뢰성을 향상시키기 위하여 소스에 연결된 필드플레이트(SCFP)를 게이트 금속 위 에 형성하였다. $\mathrm{SCFP}$ 는 게이트 금속의 단차에 의해 발생할 수 있는 불균일한 틈의 발생을 방지하기 위하여 금도금 방법으로 형성하였다. 금도금 방법으로 약 $5 \mathrm{um}$ 두께의 최종 금속막을 형성한 후 $\mathrm{SiNx}$ 절연막으로 표면을 패시베이션하면 전면 공정 이 완료된다. 소자의 동작여부를 확인하기 위한 전기적인 특성 측정을 완료한 후 $\mathrm{SiC}$ 기판을 연마하여 $85 \mathrm{um}$ 두께로 가공하 였다. ICP(Inductively Coupled Plasma) 식각장비를 이용하 여 후면에서 소스 오믹 금속까지 직접 연결되는 비아를 가공 하였다. 후면 금속막 형성을 용이하게 하기 위하여 비아는 약 82도의 경사각을 갖도록 식각 조건을 최적화 하였다. 비아의 표면을 포함하는 웨이퍼의 후면에 약 $5 \mathrm{um}$ 두께의 금을 도금 하면 소자의 제작이 완료된다. 그림 4 에는 게이트와 $\mathrm{SCFP}$ 를 포함하는 소자의 단면 전자현미경 사진과 기판을 관통하는 비 아의 단면 광학현미경 사진을 보였다.

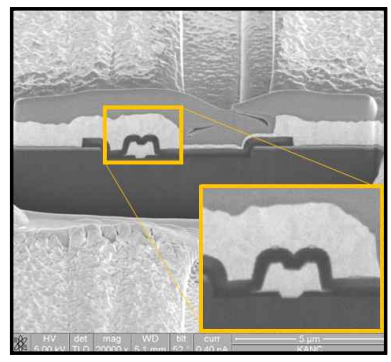

(a)

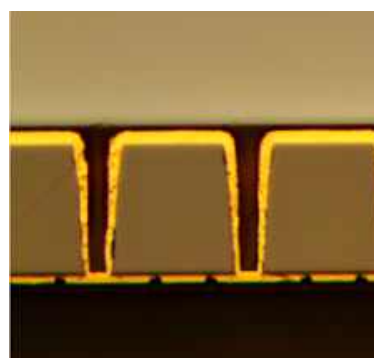

(b)
그림 4. (a) 소자의 게이트와 SCFP를 보여주는 단면 전자현미경사진과 (b) 기판을 관통하는 비아가 소스 오믹에 직접 연결되는 것을 보여주는 단면 광학현미경 사진

Fig. 4. (a) Cross-sectional electron micrograph showing the gate and SCFP of the device and (b)

Cross-sectional optical micrograph showing vias penetrating the substrate directly connected to the source ohmic

\section{3 고출력 소자와 IMFET 제조 공정}

총너비 $3.5 \mathrm{~mm}$ 인 소자를 단위소자라고 부르며 고출력의 소 자를 제작하기 위해서는 이러한 단위소자를 병렬로 연결한 형 태로 소자를 제작하여야 한다. 고출력 소자의 경우 출력 임피 던스가 상대적으로 낮아지기 때문에 패키지 내부에 임피던스 정합회로를 포함하여 입력과 출력단의 임피던스가 $50 \mathrm{ohm}$ 으 로 변환이 되도록 하면 외부 계측기 혹은 안테나 등의 회로에 연결할 때 매우 편리하며 소형화를 가능하게 해준다. 패키지 내에서 임피던스 정합을 구현한 소자를 IMFET(Internally Matched Field Effect Transistor)이라고 부른다. 그림 5에는 
8개의 단위소자가 병렬로 연결된 고출력 소자와 IMFET의 뚜 껑을 덮지 않은 상태의 사진을 보여주고 있다. 그림 5에 표시 된 고출력 소자의 위쪽이 드레인 전극이고 아래쪽이 게이트 전극이다. 드레인과 게이트 전극이 각각 8개 존재함을 알 수 있으며 각각의 전극에 $350 \mathrm{um}$ 길이의 게이트가 10 개씩 연결 되어 있다. 따라서 단위소자는 $350 \mathrm{um} \mathrm{x} 10=3.5 \mathrm{~mm}$ 의 총 게이트 너비를 갖게 되고 이를 8 개 연결한 고출력 소자는 3.5 $\mathrm{mm}$ x $8=28 \mathrm{~mm}$ 의 총 게이트 너비를 갖게 된다. $28 \mathrm{~mm}$ 소자의 크기는 $44000 \mathrm{um} \mathrm{x} 880 \mathrm{um}$ 이다. 소스의 전기적인 접촉은 비아를 통하여 소자의 뒷면에서 이루어지기 때문에 소 자 표면에 있는 소스 전극은 웨이퍼 상에서 측정이 필요할 때 에만 사용된다. 고출력 소자를 이용하여 그림 5. (b) 와 같은 IMFET을 제작하였다. 사진에서 한가운데에 있는 소자가 그림 5. (a)에 있는 총 게이트 너비 $28 \mathrm{~mm}$ 소자이며 그 양쪽에 SLC(single layer capacitor)가 위치하여 예비 정합을 이룬 다. SLC의 양쪽에 다시 alumina 기판위에 제작한 임피던스 정합회로를 추가하면 IMFET이 완성된다. $\mathrm{GaN}$ 소자는 $\mathrm{Au}: \mathrm{Sb}=80: 20$ 을 사용하여 Eutectic 접합을 하였고 나머지 부 품은 Silver epoxy를 사용하여 접합하였다. 각각의 부품은 2 mil 두께의 금선을 사용하여 전기적으로 연결하였다. 그림 5.(b)의 왼쪽이 입력단이고 오른쪽이 출력단이 된다.

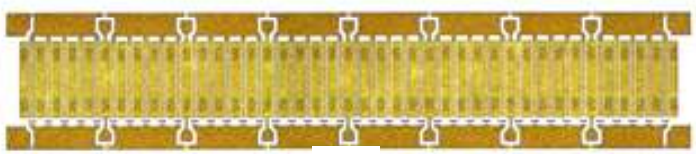

(a)

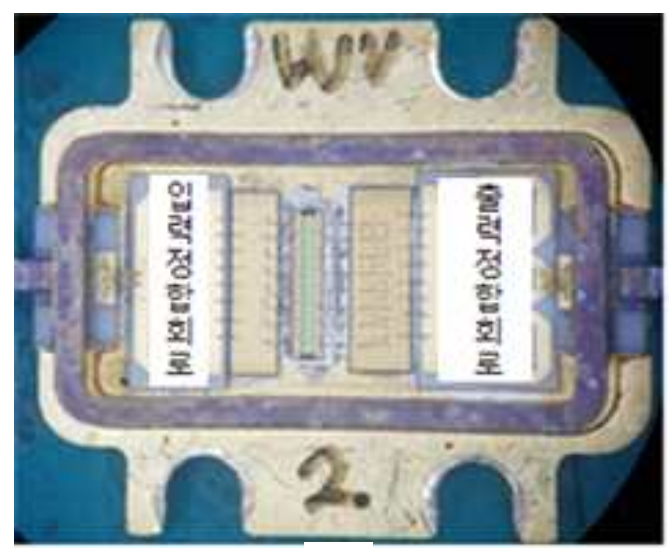

(b)

그림 5. (a) 단위소자 8개가 뱅렬로 연결된 총 게이트 너비 28 $\mathrm{mm}$ GaN HEMT 고출력 소자의 사진 (b) 위의 소자를 이용하 여 내부 정합회로를 포함하여 만든 IMFET 소자의 사진

Fig. 5. (a) Photo of a GaN HEMT high-power device with a total gate width of $28 \mathrm{~mm}$ in which 8 unit devices are connected in parallel (b) Picture of IMFET device made with internal matching circuit using the above device

\section{3. 소자의 전기적 특성, 수율 및 신뢰성}

\subsection{RF 특성}

공정이 완료된 웨이퍼에 대해서는 $\mathrm{DC}, \mathrm{RF}$ 특성을 평가하는
측정을 진행하였다. 웨이퍼 상태에서는 온도 조절상의 한계와 고출력 $\mathrm{RF}$ 신호 인가의 어려움 때문에 고출력의 소자에 대해서 는 소자에 큰 전류가 흐르는 측정이나 $\mathrm{RF}$ 가 인가된 특성의 측 정은 불가능하다. 따라서 공정관리모니터링(Process Control Monitoring, $\mathrm{PCM}$ )소자에 대해서만 소자의 모든 $\mathrm{DC}, \mathrm{RF}$ 특성 을 측정하게 된다. $\mathrm{PCM}$ 소자는 총 게이트 너비 $0.7 \mathrm{~mm}$ 의 소 자를 사용하였다. $\mathrm{PCM}$ 소자에 대하여 측정된 $\mathrm{DC}, \mathrm{RF}$ 특성 값들을 표 2에 표시하였다.

\section{표 2. $\mathrm{PCM}$ 소자에 대하여 측정된 $\mathrm{DC}, \mathrm{RF}$ 특성.}

Table 2. DC and RF characteristics measured for PCM devices.

\begin{tabular}{|c|c|c|c|c|}
\hline Test & Parameter & Test Condition & Unit & Typical \\
\hline \multirow{7}{*}{$\mathrm{DC}$} & Gm_max & $\mathrm{Vd} 10 \mathrm{~V}$ & $\mathrm{mS} / \mathrm{mm}$ & 250 \\
\hline & Idmax & $\mathrm{Vd} 10 \mathrm{~V}, \quad \mathrm{Vg} 2 \mathrm{~V}$ & $\mathrm{~mA} / \mathrm{mm}$ & 950 \\
\hline & Idlkg & $\mathrm{Vd} 10 \mathrm{~V}, \quad \mathrm{Vg}-8 \mathrm{~V}$ & $\mathrm{~mA} / \mathrm{mm}$ & 0.1 \\
\hline & Idlkg_150 & $\mathrm{Vd} \quad 150 \mathrm{~V}, \quad \mathrm{Vg}-8 \mathrm{~V}$ & $\mathrm{~mA} / \mathrm{mm}$ & 0.3 \\
\hline & Iglkg & $\mathrm{Vd} 10 \mathrm{~V}, \quad \mathrm{Vg}-8 \mathrm{~V}$ & $\mathrm{~mA} / \mathrm{mm}$ & -0.1 \\
\hline & Iglkg_150 & $\mathrm{Vd} 150 \mathrm{~V}, \quad \mathrm{Vg}-8 \mathrm{~V}$ & $\mathrm{~mA} / \mathrm{mm}$ & -0.3 \\
\hline & Vth & $\mathrm{Vd} 10 \mathrm{~V}$ & V & -2.7 \\
\hline \multirow{6}{*}{$\mathrm{RF}$} & $\mathrm{ft}$ & $\mathrm{Vd} 40 \mathrm{~V}$ & $\mathrm{GHz}$ & 19.0 \\
\hline & fmax & $\mathrm{Vd} 40 \mathrm{~V}$ & $\mathrm{GHz}$ & 41.5 \\
\hline & Gss & \multirow{2}{*}{$\begin{array}{l}\text { Vd } 50 \mathrm{~V}, \quad \text { Class B } \\
\text { Pin } 10 \mathrm{dBm}, 3.5 \mathrm{GHz}\end{array}$} & $\mathrm{dB}$ & 16.5 \\
\hline & Gp & & $\mathrm{dB}$ & 15.0 \\
\hline & Psat & \multirow{2}{*}{$\begin{array}{ll}\mathrm{Vd} 50 \mathrm{~V}, & \text { Class B } \\
\text { PAE_max, } & 3.5 \mathrm{GHz}\end{array}$} & $\mathrm{W} / \mathrm{mm}$ & 8.0 \\
\hline & PAE_max & & $\%$ & 53 \\
\hline
\end{tabular}

각 측정변수들의 기호와 정의는 다음과 같다. 표 2 의 위에서 부터, 최대 트랜스컨덕턴스(Gm_max), 최대 드레인 전류 (Idmax), 10V에서의 드레인 및 게이트 누설전류(Idlkg, Iglkg), 소자의 항복이 일어나는지를 보여주는 $150 \mathrm{~V}$ 에서의 드레인 및 게이트 누설전류(Idlkg_150, Iglkg_150), 문턱전압(threshold voltage, $\mathrm{Vth})$, 전류이득 임계주파수(ft), 전력이득 임계 주파 수(fmax), 소신호 이득(Gss), 실제인가 소신호 이득(delivered small signal power gain, $\mathrm{Gp}$ ), 포화 출력(최대 전력부가 효 율에서의 RF 출력, Psat), 최대 전력부가 효율(Power Added Efficiency, PAE) 이며 각각의 측정조건과 단위는 표에 표시 한 바와 같다.

$\mathrm{PCM}$ 소자의 특성이 규격을 만족하게 되면 기판 내에 있는 모든 고출력 소자에 대하여 전류가 소모 전력이 $10 \mathrm{~W}$ 이하의 영역에서 $\mathrm{DC}$ 특성을 측정하여 소자의 동작여부를 판단하게 된 다. 그림 6 에 이렇게 측정된 총 게이트 너비 $3.5 \mathrm{~mm}$ 인 단위 소자의 대표적인 $\mathrm{DC}$ 측정 결과를 표시하였다. 측정은 서로 다 른 세 번의 제조 공정을 통해 제작된 총 2518개의 소자에 대 하여 수행되었다. 웨이퍼 상에서 측정이 완료되면 다이아몬드 톱을 이용하여 웨이퍼를 각각의 소자의 크기에 맞도록 잘라 목적에 맞도록 내부정합소자(Internally Matched Field 


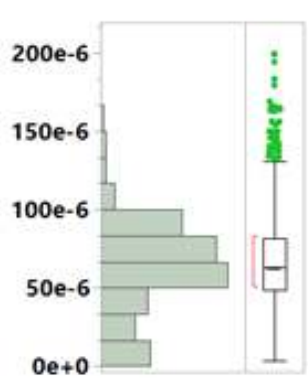

(a)

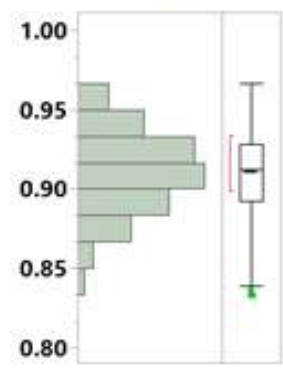

(c)

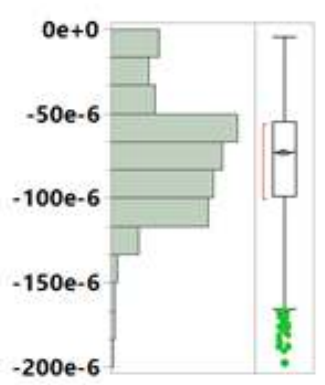

(b)

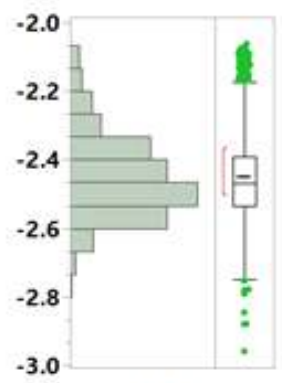

(d)
그림 6. 총 게이트 너비 $3.5 \mathrm{~mm}$ 소자에 대하여 드레인 전압 $10 \mathrm{~V}$, 게이트 전압 $-8 \mathrm{~V}$ 에서 측정한 (a) 드레인 누설전류 와 (b) 게이트 누설전류를 각각 $\mathrm{A} / \mathrm{mm}$ 단위로 표시한 것. 드레인 전압 $10 \mathrm{~V}$ 에서 측정한 (c) 드레인 최대 전류를 $\mathrm{A} / \mathrm{mm}$ 단위로 표시한 것과 $(\mathrm{d})$ 문턱전압을 $\mathrm{V}$ 단위로

$$
\text { 표시한 그림 }
$$

Fig. 6. For a device with a total gate width of 3.5 $\mathrm{mm}$, (a) drain leakage current and (b) gate leakage current measured at a drain voltage of $10 \mathrm{~V}$ and a gate voltage of $-8 \mathrm{~V}$ are expressed in units of $\mathrm{A} / \mathrm{mm}$, respectively. (C) Maximum drain current measured at 10V drain voltage in $\mathrm{A} / \mathrm{mm}$ units and (d) Threshold voltage in $\mathrm{V}$ units.

Effect Transistor, IMFET) 혹은 정합회로가 없는 단위 패키 지 소자(discrete packaged transistor)제작을 위한 패키징에 사용하게 된다.

그림 7에는 측정을 위한 평가회로에 뚜껑이 덥혀있는 상태 로 소자가 장착되고 계측장비와 연결되어 있는 상태의 사진이 다. 사진 위쪽의 전선은 게이트에 DC 전원을 인가하는 전선과 커넥터이고 아래쪽 빨간색 케이블은 드레인의 $\mathrm{DC}$ 전원이다. 왼쪽과 오른쪽의 $\mathrm{SMA}$ 커넥터로 연결된 전선이 각각 $\mathrm{RF}$ 신호 의 입력과 출력을 나타낸다. 평가회로(Evaluation Board)위에 는 $\mathrm{DC}$ 인가를 위한 간단한 회로만 있을 뿐 $\mathrm{RF}$ 회로에는 50 $\mathrm{ohm}$ 전송선을 제외하면 매우 간단하게 연결되어 있음을 알 수 있다.

그림 8에는 이렇게 제작된 IMFET 25개에 대한 측정결과를 표시하였다. S-band 대역이고 $400 \mathrm{MHz}$ 대역폭에서 각각 출 력 $186.5 \mathrm{~W}$ 이상, 소신호 이득 $13.2 \mathrm{~dB}$ 이상, 고출력에서의

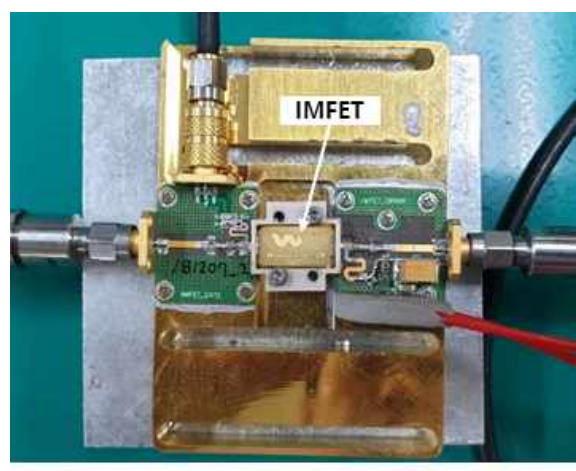

그림 7. 고출력 IMFET소자의 $\mathrm{RF}$ 특성을 측정하기 위하여 평가회로위에 장착된 모습

Fig. 7. Mounted on the evaluation circuit to measure the RF characteristics of a high-power IMFET device

게인 $9.7 \mathrm{~dB}$ 이상, 드레인 효율 $63.3 \%$ 이상을 보였다. 측정은 드레인 전압 $50 \mathrm{~V}$, Class B 조건에서 펄스폭 $100 \mathrm{us,} \mathrm{duty}$ $15 \%$ 로 실행되었다.

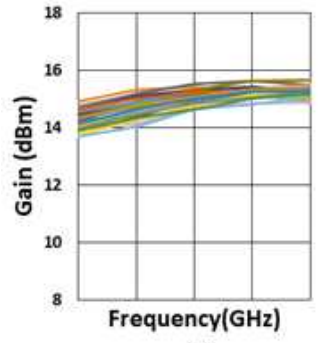

(a)

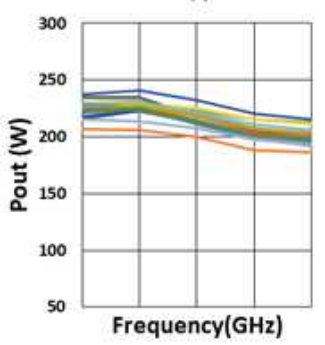

(c)

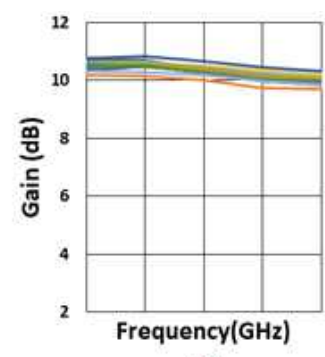

(b)

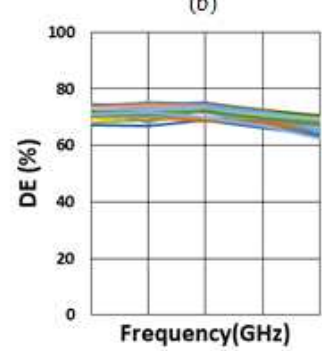

(d)
그림 8. IMFET의 RF 측정결과. (a) 소신호 이득 $(\mathrm{Pin}=-17 \mathrm{dBm}), \operatorname{Pin}=43 \mathrm{dBm}$ 에서의 $(\mathrm{b})$ 이득, (c) 출력, (d) 드레인 효율. 드레인 전압 $50 \mathrm{~V}$, class B, 100 us 펄스, duty 15\%, 주파수는 s-band에서 $400 \mathrm{MHz}$ 의 대역폭에 대하여 측정

Fig. 8. RF measurement result of IMFET. (a) Small signal gain $($ Pin $=-17 \mathrm{dBm})$, $(\mathrm{b})$ gain at Pin = $43 \mathrm{dBm}$, (c) output, (d) drain efficiency. Drain voltage 50V, class B, 100 us pulse, duty $15 \%$, frequency measured for a bandwidth of $400 \mathrm{MHz}$ in s-band.

3.2 신뢰성

제작된 소자들의 신뢰성을 확인하기 위하여 단위소자를 이 
용한 기술적합성시험(Technology Qualification Test)과 고출 력 소자를 이용한 제품적합성시험(Product Qualification)으로 나누어 시험하였다. 기술적합성시험은 제작된 소자가 가지고 있는 고유 신뢰성(intrinsic reliability)을 평가하는 것으로 가 속수명시험 (Accelerated Life Test, ALT)을 포함하는 광범위 한 신뢰성 시험을 단위소자인 게이트 폭 $3.5 \mathrm{~mm}$ 소자에 대하 여 수행하였다. 표 3에 기술적합성시험 항목들과 측정 조건 및 그 결과를 요약 하였다.

\section{표 3. 총 게이트 폭 $3.5 \mathrm{~mm}$ 인 단위소자에 대하여 수행한 신뢰성 시험 항목과 그 결과}

Table 3. Performed on a unit device with a total gate width of $3.5 \mathrm{~mm}$. Reliability test items and their results.

\begin{tabular}{|c|c|c|c|c|}
\hline 시험 & 내용 & 조건 & 결과 & 참고자료 \\
\hline EVA & $\begin{array}{c}\text { Visual } \\
\text { Inspection }\end{array}$ & $\begin{array}{c}\text { Optical } \\
\text { Microscope, All }\end{array}$ & Pass & $\begin{array}{l}\text { MIL-STD } \\
-883 \mathrm{G}^{[9]}\end{array}$ \\
\hline ED & $\begin{array}{l}\text { Electrical } \\
\text { Test }\end{array}$ & $\begin{array}{c}\mathrm{DC} / \mathrm{RF} \\
\text { Characterization } \\
\text { All }\end{array}$ & Pass & $\begin{array}{l}\text { MIL-STD } \\
-883 \mathrm{G}\end{array}$ \\
\hline BPS & $\begin{array}{l}\text { Bond Pull } \\
\text { Strength }\end{array}$ & $\begin{array}{c}\text { Bond Pull } \\
\text { Stress, Sampled }\end{array}$ & Pass & $\begin{array}{l}\text { MIL-STD } \\
-883 \mathrm{G}\end{array}$ \\
\hline $\mathrm{TC}$ & $\begin{array}{l}\text { Temperature } \\
\text { Cycling }\end{array}$ & $\begin{array}{l}\mathrm{T} \text { Tlow }=-65{ }^{\circ} \mathrm{C}, \\
\mathrm{T} \text { high }=150 \\
{ }^{\circ} \mathrm{C}, 500 \text { cycles }\end{array}$ & Pass & $\begin{array}{c}\mathrm{JESD} 22-\mathrm{A} 104 \\
-\mathrm{D}^{[10]}\end{array}$ \\
\hline $\begin{array}{l}\text { ESD- } \\
\text { HBM }\end{array}$ & $\begin{array}{c}\text { Human } \\
\text { Body Model }\end{array}$ & $\begin{array}{c}\text { Electro-Static } \\
\text { Discharge Test }\end{array}$ & $\begin{array}{c}\text { Class } \\
1 \mathrm{~B}\end{array}$ & $\begin{array}{c}\text { JESD22-A114 } \\
-\mathrm{F}^{[11]}\end{array}$ \\
\hline $\begin{array}{l}\text { ESD- } \\
\text { CDM }\end{array}$ & $\begin{array}{l}\text { Charge } \\
\text { Device } \\
\text { Model }\end{array}$ & $\begin{array}{l}\text { Electro-Static } \\
\text { Discharge Test }\end{array}$ & $\begin{array}{l}\text { Class } \\
\text { IV }\end{array}$ & $\begin{array}{c}\mathrm{JESD} 22-\mathrm{C} 101 \\
-\mathrm{F}^{[12]}\end{array}$ \\
\hline HTST & $\begin{array}{l}\text { High Temp. } \\
\text { Storage } \\
\text { Test }\end{array}$ & $150{ }^{\circ} \mathrm{C}, 1000 \mathrm{~h}$ & $\begin{array}{l}\text { No } \\
\text { Fail }\end{array}$ & $\begin{array}{c}\mathrm{JESD} 22-\mathrm{A} 103 \\
-\mathrm{E}^{[13]}\end{array}$ \\
\hline ALT & $\begin{array}{l}\text { Accelerated } \\
\text { Life Test }\end{array}$ & $\begin{array}{c}\text { Temperature } \\
\text { Test }\end{array}$ & $\begin{array}{c}\mathrm{Ea}= \\
1.59 \mathrm{eV}\end{array}$ & MIL-STD-883G \\
\hline HTOL & $\begin{array}{l}\text { High Temp. } \\
\text { Operating } \\
\text { Life }\end{array}$ & $\begin{array}{c}\mathrm{V} D=50 \mathrm{~V}, \\
\mathrm{Tj}=259{ }^{\circ} \mathrm{C}, \\
1000 \mathrm{~h}\end{array}$ & $\begin{array}{c}\text { FIT }= \\
625\end{array}$ & $\begin{array}{c}\text { JESD22-A108 } \\
-\mathrm{F}^{[14]}\end{array}$ \\
\hline HTRB & $\begin{array}{l}\text { High Temp. } \\
\text { Reverse } \\
\text { Bias }\end{array}$ & $\begin{array}{c}\mathrm{Vd}=150 \mathrm{~V}, \\
\mathrm{Vg}=-8 \mathrm{~V}, \mathrm{Tc}= \\
150^{\circ} \mathrm{C}, 1000 \mathrm{~h}\end{array}$ & $\begin{array}{l}\text { No } \\
\text { Fail }\end{array}$ & $\begin{array}{c}\text { JESD22-A108 } \\
-\mathrm{F}\end{array}$ \\
\hline
\end{tabular}

표 3에 있는 시험 항목들은 미국 국방부(Department of Defence, DOD)에서 관리하는 Mil-std 표준과 미국 군수와 민 수 전자업계를 통괄하는 표준관리기관인 통합 전자부품개발협 회(Joint Electron Device Engineering Council, JEDEC)에 서 규정하는 전자부품 신뢰성 시험규정을 따라서 수행하였다. 육안검사 (External Visual Inspection)와 전기적 특성 검사 (Electrical Test), 패키지된 소자의 내구성을 시험하는 접합강 도시험 (Bond Pull Strength), 온도 변화 (Temperature Cycle) 시험 고온 저장 (High Temperature Storage Test)을 통과 하였다. 방전시험에서는 인체모델 (Human Body Model) 시험과 충전기기모델 (Charge Device Model)에서 각각 Class1B (500V), ClassIV (1000V)의 결과를 얻었다. 소자에 전원을 인가하고 고온으로 가속시켜 수행하는 시험인 가속수 명시험 (Accelerated Life Test, ALT), 고온 동작 (High Temperature Life Test, HTOL), 고온 역전압인가시험 (High Temperature Reverse Bias)을 수행하였다. 고온 동작시험은 최대 동작온도 (Max Rated Junction Temperature, 225 C)
보다 높은 $\mathrm{Tj}=259$ C에서 132 개의 소자에 대하여 1000 시간 수 행하여 고장이 없었고 이를 통하여 고장률(Failure in Time, FIT, 10억 시간당 고장횟수) 625를 얻었고 동작전압의 3배인 $150 V$ 에서 77 개의 소자에 대하여 1000시간 동안 수행한 고온 역전압인가시험에서도 고장이 발생하지 않았다. 가속수명시험 에서는 활성화 에너지 (Activation Energy, Ea) $1.59 \mathrm{eV}$ 를 얻었으며 최대 동작온도, 225 C에서의 평균 수명(Mean Time To Fail, MTTF)은 4.3x106 시간으로 계산되었다. 가속수명시 험의 결과를 그림 9 에 표시하였다.

가속수명시험은 $\quad \mathrm{Vd}=50 \mathrm{~V}, \quad \mathrm{Id}=0.4 \mathrm{~A}$ 의 소모전력(Power

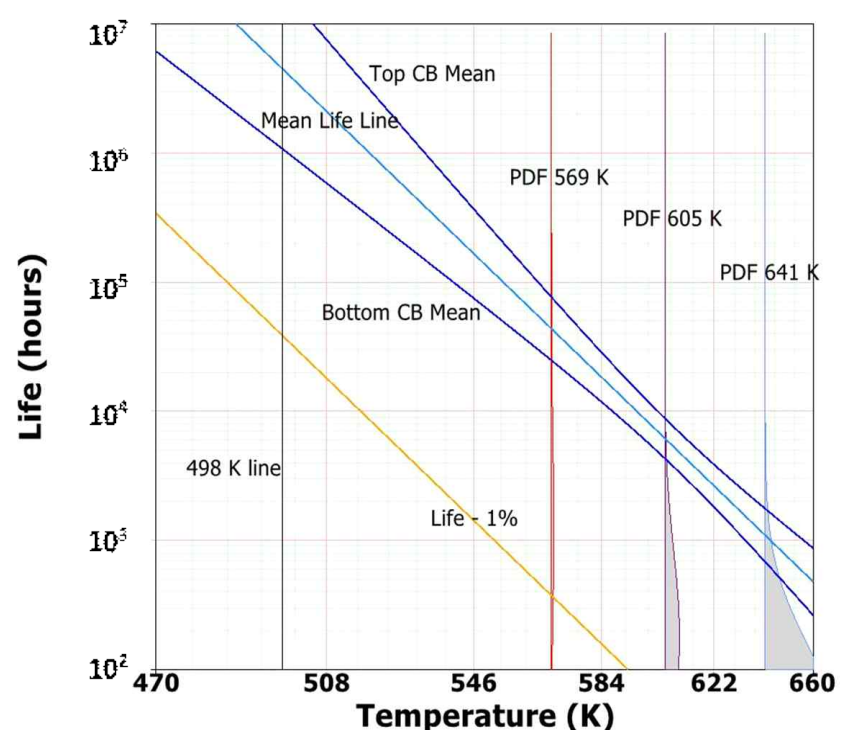

그림 9. 가속수명 시험 결과. 3가지의 소자 온도(junction Temperature), 294, 333, $372 \mathrm{C}$ 에서 각각 27개의 단위소자를 사용하여 수행하였다. 하늘색 선은 MTTF, 남색 선은 $90 \%$ 신뢰수간 (Confidence Bound, $\mathrm{CB}$ ), 노란색 선은 1\% 고장곡선,

검은색 선은 최대 사용 온도인 225 C지점을 나타낸다.

Fig. 9. Accelerated life test results. It was carried out using 27 unit devices at 3 junction temperatures, 294, 333, and $372 \mathrm{C}$, respectively. The sky blue line represents the MTTF, the blue line represents the $90 \%$ Confidence Bound (CB), the yellow line represents the $1 \%$ failure curve, and the black line represents the maximum operating temperature of $225 \mathrm{C}$

Dissipation)을 유지하였다. 소자의 고장(Failure)은 전기적 과 부하(Electrical Overstress) 혹은 최대 드레인 전류 $10 \%$ 감 소로 정의하였다. 수명 분석은 고장이 소자의 온도에 의해 일 어난다는 가정 하에 Arrhenius 모델을 사용하여 고장시간은 로그정규분포함수 (Log Normal Distribution Function)로 분석하였다.

기술적합성시험이 성공적으로 완료되었으므로 같은 기술을 이용한 다양한 크기의 소자들에 대해서는 가속 수명시험 등을 포함하지 않는 간단한 신뢰성 시험을 수행하는 제품적합성 시 험을(Product Qualification) 수행하였다. 표 4에 육안검사, 
전기적 특성검사, 접합강도시험을 통과한 소자들에 대하여 추 가적으로 수행한 제품적합성 시험 항목과 그 결과를 요약 하 였다.

\section{표 4. 총 게이트 너비 $28 \mathrm{~mm}$ 소자를 이용한 제품적합성 시험 항목과 그 결과}

Table 4. Using a device with a total gate width of $28 \mathrm{~mm}$ Product suitability test items and results

\begin{tabular}{|c|c|c|c|c|}
\hline 시험 & 내용 & 조건 & 결과 & 참고자료 \\
\hline $\mathrm{TC}$ & $\begin{array}{c}\text { Temperature } \\
\text { Cycling }\end{array}$ & $\begin{array}{c}\mathrm{T}_{-} \text {low }=-55{ }^{\circ} \mathrm{C}, \\
\mathrm{T} \text { high }=150 \\
{ }^{\circ} \mathrm{C}, 25 \text { ea, } \\
1000 \text { cycles }\end{array}$ & Pass & JESD22-A104-D \\
\hline $\begin{array}{l}\text { ESD- } \\
\text { HBM }\end{array}$ & $\begin{array}{c}\text { Human } \\
\text { Body Model }\end{array}$ & $\begin{array}{c}\text { Electro-Static } \\
\text { Discharge } \\
\text { Test, 3ea }\end{array}$ & $\begin{array}{l}\text { Class } 2 \\
(2000 \mathrm{~V})\end{array}$ & JESD22-A114-F \\
\hline $\begin{array}{l}\text { ESD- } \\
\text { CDM }\end{array}$ & $\begin{array}{l}\text { Charge } \\
\text { Device } \\
\text { Model }\end{array}$ & $\begin{array}{c}\text { Electro-Static } \\
\text { Discharge } \\
\text { Test, 3ea }\end{array}$ & $\begin{array}{c}\text { Class III } \\
(500 \mathrm{~V})\end{array}$ & JESD22-C101-F \\
\hline HTST & $\begin{array}{c}\text { High Temp. } \\
\text { Storage } \\
\text { Test }\end{array}$ & $\begin{array}{c}200{ }_{2}^{\circ} \mathrm{C}, 72 \mathrm{~h}, \\
25 \mathrm{ea}\end{array}$ & No Fail & JESD22-A103-E \\
\hline HTOL & $\begin{array}{l}\text { High Temp. } \\
\text { Operating } \\
\text { Life }\end{array}$ & $\begin{array}{c}\mathrm{V} D=50 \mathrm{~V} \\
\mathrm{Tcase}^{\circ}=85^{\circ} \mathrm{C}, \\
78 \text { ea, } 1000 \mathrm{~h}\end{array}$ & No Fail & JESD22-A108-F \\
\hline
\end{tabular}

제품 적합성 시험의 시험조건은 제품이 실제 사용되는 모듈 에서의 온도와 동작조건에 준하여 결정되었으며 수행한 모든 시험을 성공적으로 통과하였다.

\section{3 수율}

총 게이트 길이 $28 \mathrm{~mm}$ 소자의 수율을 알아보기 위하여 웨 이퍼 제조 공정이 완료된 후 $\mathrm{PCM}$ 소자의 특성이 정상적인 웨 이퍼에 대하여 웨이퍼 상에 있는 모든 $28 \mathrm{~mm}$ 소자에 대하여 $\mathrm{DC}$ 특성 측정을 하였다. 표 5에 측정 변수와 측정 조건 및 사 양을 나타내었다.

\section{표 5. 총 게이트 너비 $28 \mathrm{~mm}$ 소자의 \\ 전수 측정 변수, 조건 및 사양}

Table 5. Total gate width $28 \mathrm{~mm}$ device total measurement parameters, conditions and specifications

\begin{tabular}{|c|c|c|c|c|}
\hline 변수 & 단위 & 측정 조건 & 상한 & 하한 \\
\hline Iglkg & $\mathrm{mA} / \mathrm{mm}$ & $\begin{array}{c}\mathrm{Vd}=10 \mathrm{~V}, \\
\mathrm{Vg}=-8 \mathrm{~V}\end{array}$ & 0 & -0.1 \\
\hline Idlkg & $\mathrm{mA} / \mathrm{mm}$ & $\begin{array}{c}\mathrm{Vd}=10 \mathrm{~V}, \\
\mathrm{Vg}=-8 \mathrm{~V}\end{array}$ & 0.1 & 0 \\
\hline Iglkg_150 & $\mathrm{mA} / \mathrm{mm}$ & $\begin{array}{c}\mathrm{Vd}=150 \mathrm{~V}, \\
\mathrm{Vg}=-8 \mathrm{~V}\end{array}$ & 0 & -1 \\
\hline Idlkg_150 & $\mathrm{mA} / \mathrm{mm}$ & $\begin{array}{c}\mathrm{Vd}=150 \mathrm{~V}, \\
\mathrm{Vg}=-8 \mathrm{~V}\end{array}$ & 1 & 0 \\
\hline Vth & $\mathrm{V}$ & $\begin{array}{c}\mathrm{Vd}=10 \mathrm{~V}, \\
\mathrm{Id}=1 \mathrm{~mA} / \mathrm{mm}\end{array}$ & -2 & -4 \\
\hline
\end{tabular}

최근 공정에서 제작한 3 개의 웨이퍼에 대한 수율을 측정하 였으며 그 측정 결과를 그림 10에 표시하였다.
그림 10 에 나타낸 세장의 웨이퍼는 각각 $83.0 \%, 91.7 \%$, $84.5 \%$ 의 수율을 보였다. 그림 10 에서 웨이퍼 상에 13곳에 소 자가 존재하지 않는 부분이 있는데 이는 공정 검증을 위한 소 자(Process Control Monitoring devices, PCM)가 존재하는 영역이다.

(a)

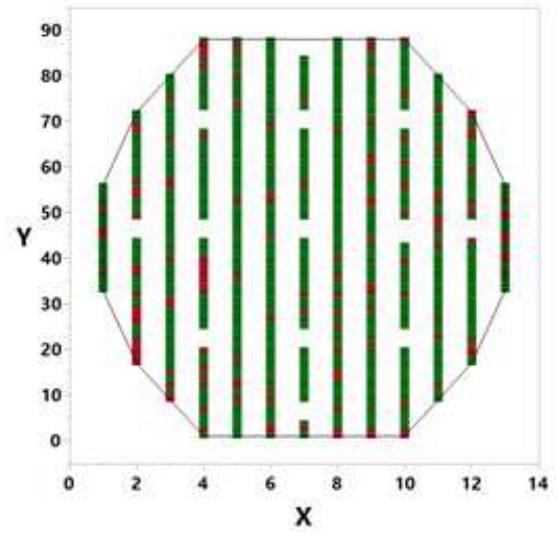

(b)

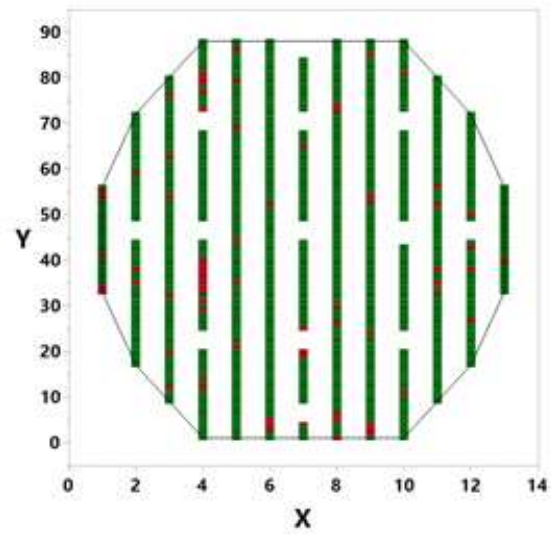

(c)

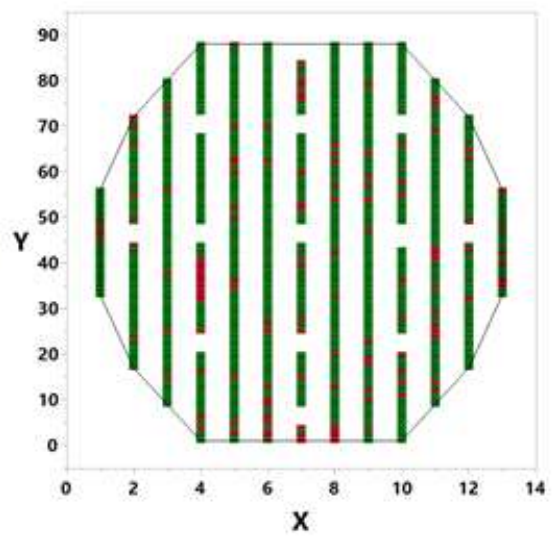

그림 10. 세장의 웨이퍼에 대한 전수 측정 결과. 초록색은 양품을 빨간색은 불량품을 나타낸다.

웨이퍼당 867개의 소자를 측정하였음.

Fig. 10. Total measurement results for three wafers. Green indicates good products and red indicates defective products. 867 devices were

\section{4. 결 론} measured per wafer.

국내에서 여러 대학과 연구소에서 지난 10 여 년간 $\mathrm{GaN}$ 
HEMT소자에 대한 연구를 수행하여 왔으나 이를 대구경 웨이 퍼위에서 양산 설비를 이용하여 대량으로 제작하고 이의 신뢰 성과 수율을 검증한 결과는 본 논문이 처음이다. 모든 제조 설 비는 4" 웨이퍼에 대하여 양산이 가능하도록 설계되었고 웨이 퍼 제조는 컴퓨터를 이용한 생산관리시스템 (Manufacturing Execution System, MES)을 이용하여 수행되었다. 공정개발 이 완료된 후 10 회 이상의 공정이 동일한 공정 조건으로 반복 적으로 수행되었고 이를 통하여 제작된 소자들에 대하여 다양 한 신뢰성 시험을 성공적으로 수행하였다. 최종적으로 총 게이 트 너비 $28 \mathrm{~mm}$ 소자에 대하여 평균 86.7\%의 수율을 얻었다. 이렇게 제작된 고출력 소자들을 이용하여 내부 정합 소자 (IMFET)를 제작하여 S-band $400 \mathrm{MHz}$ 대역에서 출력 $186.5 \mathrm{~W}$ 이상, 소신호 이득 $13.2 \mathrm{~dB}$ 이상, 드레인 효율 $63.3 \%$ 이상을 확보하였다. IMFET상태의 소자들에 대하여도 다양한 신뢰성 시험을 수행하였으며 성공적인 결과를 얻었다. 이러한 결과들은 S-band에서 $180 \mathrm{~W}$ 급 혹은 그 이하 출력의 소자는 국내에서 양산이 가능하게 되었음을 의미한다. 현재 이 기술을 이용한 다양한 군수 및 민수 응용을 위한 제품 개발과 위탁생 산(foundry) 서비스를 준비 중에 있으며 더 높은 주파수, 다양 한 성능을 갖는 집적 회로(Monolithic Microwave Integrated Circuit, MMIC), 다양한 출력을 갖는 소자개발에 대한 국가적 인 지원이 절실한 상태이다.

\section{Aknowlegement}

본 논문은 한국 국방과학연구소(ADD: Agency of Defense Development)의 연구개발 프로그램UC150019FD의 지원을 받아 작성되었습니다. 4차산업혁명과 $\mathrm{GaN}$ 소자의 연관관계에 대해 많은 의견을 준 웨이비스의 김현제 전무님과 기획팀, 소 자의 개발과 제작을 위해 도움을 준 소자 설계팀, 소자 공정 팀, 소자 제조팀, IMFET설계와 제작을 담당한 PA 개발팀, PA 제조팀, 신뢰성 시험팀 연구원과 직원들에게 감사한 마음을 전 합니다. 과제의 기획을 위해 노력해 주신 웨이비스의 강운규 사장님과 과제 수행기간동안 많은 격려와 조언을 아끼지 않으 신 국방과학연구소의 염동진, 양진모 팀장님, 최준호 연구원님 께도 감사드립니다. 참여기관으로 함께 연구한 전자통신연구원 의 연구원분들과 경북대학교의 이정희 교수님 연구실 연구원 들께도 감사드립니다. 본과제의 기획과 성공, 그리고 이를 통 한 GaN HEMT소자 제조 기술의 국산화은 이 모든 분들의 도 움 없이는 가능하지 않았을 것입니다.

\section{References}

[1] Hoque, A. K. M. Fazlul, 4th Industrial RevolutionImpact and Challenges, National Conference on Electronics and Informatics, 2019

[2] S. Park, "Strategic Reviews on Promoting the Fourth Industrial Revolution by Supplying 5G Additional Frequency" Electronics and Telecommunications Trends, vol. 34, no. 6, pp. 1-16, Dec. 2019.
[3] N. Kaminski, O. Hilt, "SiC and GaN devices - wide bandgap is not all the same." Circuits, Devices \& Systems, IET. 8. 227-236. 2014.

[4] S. Sano, K. Ebihara, T. Yamamoto, T. Sato, N. Miyazawa, "GaN HEMTs for wireless communication.”, SEI Technical Review. 65-70, 2018.

[5] W. Johnson, E. Piner, "GaN HEMT technology.", Springer Series in Materials Science 156(1), 209-237, 2012.

[6] R. Fury , J. B. Barner , B. Pribble , J. Fisher, D. A. Gajewski, F. Radulescu, H..Hagleitner, D. Namishia, Z. Ring, J. Gao, S. Lee, B. Fetzer, R. Mcfarl, J. Milligan, J. Palmour, "GaN-on-SiC MMIC Production for S-Band and EW-Band Applications”, International Conference of CS Mentech, 2013

[7] D. Youn, J. Lee, V. Kumar, K. Lee, J. Lee, A. Ilesanmi, "The Effects of Isoelectronic Al Doping and ProcessOptimization for the Fabrication of High-PowerAlGaN-GaN HEMTs.”, Electron Devices, IEEE Transactions on. 51. 785 - 789, 2004.

[8] S. Lee, Y. Jung, B. Jun, C. Choi, S. Choi, M. Han, S. Lee, H. Lee, M. Song, J. Kwon, M. Park, S. Lee, Y. Kim, H. Jung, Y. Lee, H. Kwon, " Performance of 0.4 um gate $\mathrm{AlGaN} / \mathrm{GaN}$ HEMT on $\mathrm{SiC}$ substrate with electro-plated source connected field plate.", AWAD, 2017

[9] Military Specification (MIL)-STD-883, “TEST METHOD STANDARD MICROCIRCUITS”, revision G (DOD, 20 June 2014).

[10] JEDEC Standard JESD22-A104, “Temperature Cycling”, revision D (JEDEC, May 2005)

[11] JEDEC Standard JESD22-A114, "Electrostatic Discharge (ESD) Sensitivity Testing Human Body Model (HBM)", revision F (JEDEC, January 2007)

[12] JEDEC Standard JESD22-C101, "Field-Induced Charged-Device Model Test Method for Electrostatic-Discharge-Withstand Thresholds of Microelectronic Components", revision F (JEDEC, December 2009)

[13] JEDEC Standard JESD22-A103, "High Temperature Storage Life”, revision E (JEDEC, October 2015)

[14] JEDEC Standard JESD22-A108, “TEMPERATURE, BIAS, AND OPERATING LIFE”, revision F (JEDEC, July 2017) 